\title{
Epidemiology of Urological Emergencies at the Regional University Hospital Center of Ouahigouya, Burkina Faso
}

\section{Mamadou Tiéoulé Traore ${ }^{1 *}$, Clôtaire Alexis Marie Kiemdiba Donega Yameogo ${ }^{2}$, Moussa Kabore ${ }^{1}$, Souleymane Ouedraogo ${ }^{1}$}

${ }^{1}$ Service de chirurgie du CHU régional de Ouahigouya, Ouahigouya, Burkina Faso

${ }^{2}$ Service d'urologie du CHU Yalgado Ouédraogo Ouagadougou, Ouaga, Ouagadougou, Burkina Faso

Email: ^t.mamadou.t@gmail.com,t_mamadou@yahoo.fr

How to cite this paper: Traore, M.T., Yameogo, C.A.M.K.D., Kabore, M. and Ouedraogo, S. (2020) Epidemiology of Urological Emergencies at the Regional University Hospital Center of Ouahigouya, Burkina Faso. Open Journal of Urology, 10, 177-183. https://doi.org/10.4236/oju.2020.106020

Received: March 6, 2020

Accepted: May 10, 2020

Published: May 13, 2020

Copyright ( 2020 by author(s) and Scientific Research Publishing Inc. This work is licensed under the Creative Commons Attribution International License (CC BY 4.0).

http://creativecommons.org/licenses/by/4.0/

\begin{abstract}
Introduction: Urological emergencies are less frequent compared to other emergencies, particularly traumatological and digestive emergencies. The objective of this study was to determine the epidemiological profile of urological emergencies in a regional hospital in Burkina Faso. Patients and methods: This was a cross-sectional study of urological emergencies admitted to the Surgical Department of the Ouahigouya Regional University Hospital in Burkina Faso over a period of 41 months. The study covered a 41-month period from March 2015 to July 2018. Ethical clearance was taken from the institutional ethics committee. Results: Urological emergencies accounted for 3.7\% of all emergencies. The mean age of the patients was $56.59 \pm 25.93$ years (range 1 year - 95 years). The sex ratio was 12.05 . Bladder urinary retention was the main urological emergency in $48.28 \%$ of cases. Suprapubic cystostomy was the most performed surgical procedure $(56.25 \%)$ followed by debridement of external genitalia gangrene (27.68\%). Conclusion: Urological emergencies occupy a significant place in our work context. An increase in the number of urologists would improve their management.
\end{abstract}

\section{Keywords}

Epidemiology, Urological Emergencies, Retention, Cystostomy

\section{Introduction}

Emergency very often rhymes with suffering for the patient and those around him, hence the need for rapid treatment [1]. Urological emergencies are less frequent compared to other surgical emergencies, notably trauma and digestive 
[2]. Their care is an important part of the activity of a urology service [3] [4]. However, this activity is often underestimated in the urology departments [5]. It is therefore understandable that it is even more underestimated in the services that accommodate all emergencies. In Africa there is generally no individualized unit for the management of urological emergencies. In several studies, bladder retention appears to be the most common urological emergency [3] [4] [6]. These urological emergencies mainly concern the elderly. This therefore requires special attention in the therapeutic approach. Also, it should be noted that there is a lack of urologists in some African countries. The objective of this work was therefore to determine the epidemiological profile of urological emergencies in a regional hospital in Burkina Faso.

\section{Patients and Method}

This was a cross-sectional retrospective study of urological emergencies admitted to the surgery department of the regional university hospital center (CHUR) of Ouahigouya in Burkina Faso. The study covered a 41-month period from March 2015 to July 2018. Data were collected from hospital records, operative report registers and patient records. The variables studied were age, sex, profession, type of emergency and type of gesture performed. The data was analyzed using Statistical Package for the Social Sciences (SPSS) software in version 21.0. The figures and tables were produced using Excel 2013 software.

Ethical clearance was taken from the institutional ethics committee.

\section{Results}

We collected 261 urological emergencies during the study period, or an average of 76.39 urological emergencies per year. Urological emergencies accounted for $3.7 \%$ (261/7050) of all surgical emergencies admitted during the study period. The mean age of the patients was $56.59 \pm 25.93$ years with extremes of 1 year and 95 years. In our series, $52.49 \%(137 / 261)$ of the patients were at least 60 years old. The sex ratio was 12.05. Farmers were the most represented socio-professional category in $46.4 \%$ of the cases. Bladder retention was the main urological emergency in $48.28 \%$ of the cases.

Table 1 provides a breakdown of the different types of urological emergencies.

Prostate tumor was the primary etiology of urinary bladder retention in $89.68 \%$ of cases.

Figure 1 shows the distribution of patients according to the etiology of urinary bladder retention.

Table 2 shows the distribution of patients according to the etiology of urinary bladder retention.

Bladder tumor was the main etiology of total hematuria in $78.95 \%(15 / 19)$. Urogenital trauma accounted for $6.51 \%$ of urological emergencies. Trauma to the urethra accounted for $47.06 \%$ of urogenital trauma. One hundred and twelve (42.91\%) patients underwent surgery. The suprapubic cystostomy was the most performed surgical procedure (56.25\%) followed by debridement of gangrene of 
the external genitalia (27.68\%).

Table 3 gives the distribution of patients according to the surgical procedure performed.

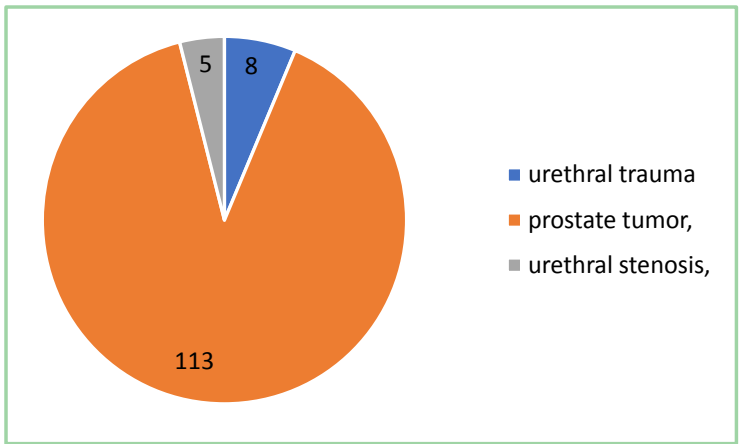

Figure 1. Étiology of urine retention.

Table 1. Distribution of patients by type of urological emergency.

\begin{tabular}{ccc}
\hline Type of emergency & Effective & Percentage (\%) \\
\hline Bladder retention of urine & 126 & 48.28 \\
Urogenital infections & 52 & 19.92 \\
* Fournier gangrene & 31 & 11.88 \\
* Acute orchiepididymitis & 12 & 4.6 \\
* Acute pyelonephritis & 4 & 1.53 \\
* Hydrocele infected & 3 & 1.15 \\
* Acute prostatitis & 2 & 0.77 \\
Renal colic & 30 & 11.49 \\
Total hematuria & 19 & 7.28 \\
Spermatic cord twist & 11 & 4.21 \\
Urogenital trauma & 17 & 6.51 \\
Priapism & 5 & 1.91 \\
Complication of circumcision & 1 & 0.38 \\
Total & 261 & 100 \\
\hline
\end{tabular}

Table 2. Distribution of patients according localization of urological traumatism.

\begin{tabular}{ccc}
\hline Geste & Effectif & Pourcentage (\%) \\
\hline Uretral trauma & 8 & 47.06 \\
Renal contusion & 3 & 17.65 \\
Bladder rupture & 3 & 17.65 \\
Closed scrotal trauma & 1 & 5.88 \\
Penis trauma & 2 & 11.76 \\
Total & 17 & 100 \\
\hline
\end{tabular}

Table 3. Distribution of patients according to the surgical procedure performed.

\begin{tabular}{ccc}
\hline Act & Effective & Percentage (\%) \\
\hline Suprapubic cystostomy & 63 & 56.25 \\
Debridement & 31 & 27.68 \\
Scrotal exploration/orchidopexy & 11 & 9.82 \\
Al-Ghorab & 5 & 4.46 \\
Exploration-suture scrotal wound & 2 & 1.78 \\
Total & 112 & 100 \\
\hline
\end{tabular}




\section{Discussion}

Urological emergencies accounted for 3.7\% of all surgical emergencies admitted to the surgical department during the study period with an average of 76.39 cases per year. This result is similar to that reported by Mpirimbanyi in Rwanda who estimated the frequency of urological emergencies at $5.3 \%$ in a general surgery department [7]. However, Diabaté and Diallo estimated respectively at $15.80 \%$ and $22 \%$ the share of urological emergencies in urological consultations. These two authors also reported an average of 140.9 cases/year and 253.33 cases/year respectively [1] [3]. In fact, these two authors conducted their study in a urology department. This is not the case in our hospital where there is no individual unit for the management of urological emergencies. All surgical emergencies are therefore admitted to a single surgery department. It should be noted that certain urological emergencies such as urinary bladder retention are often taken care of in peripheral health facilities before being referred to the CHUR for external consultation. Anything that reduces the number of urological emergencies we receive.

The average age of our patients was 56.59 years. This result is similar to that reported in several studies. Martin in France reported an average age of 57 years [4]. In Africa Diallo, Diabaté and Fall reported an average age of 56, 59 and 58.8 years, respectively [1] [3] [6]. Prostatic pathologies are responsible for the majority of urological emergencies and occur beyond the fifth decade [6] [8].

We noted a clear male predominance in our series with a sex ratio of 12.05. Indeed, this male predominance is reported in almost all studies on urological emergencies [2] [5] [6] [9] [10]. This is linked to the high frequency of emergencies linked to urethro-prostatic pathologies [3].

Urinary bladder retention was the most frequent urological emergency in our series with $48.28 \%$ of cases. In the literature, the same observation has been made by several authors. Diallo and Fall reported a frequency of $73.9 \%$ and 60.6\% respectively [1] [6]. Also, in Martin's study bladder retention was the first urological emergency with $24.11 \%$ of cases [4]. Bladder retention of urine is the main reason for the discovery of prostate tumors [6]. In Africa, patients generally consult health facilities only at the stages of complications due to certain socio-economic and cultural constraints [6]. The first symptoms of the prostate tumor do not generally worry the patient. Also, what affects the urogenital system is often considered taboo by the elderly subject.

Urogenital infections ranked second in our series with $19.92 \%$ of cases. Diabaté reported a similar result (19.80\%) [3]. On the other hand, in the Topaktas series in Turkey, urogenital infections represented the first urological emergency [10]. Gangrene of the external genitalia accounted for $59.61 \%$ of these urogenital infections in our series. It is a rapidly progressive necrotizing fasciitis of the perineum and external genitalia resulting from a polymicrobial infection [11]. His prognosis remains serious despite the progress of resuscitation. The mortality rate varies between $16 \%$ and $40 \%$ and can reach $80 \%$ in certain series [12] [13].

Kidney colic was the third urological emergency in our series with $11.5 \%$ of 
cases. In the Diallo series, she only came in fourth position [1]. By cons in the series of Topaktas and Martin it represented the second urological emergency [4] [10]. In India renal colic was the first urological emergency in Talreja's study [2]. In France renal colic represents approximately $1 \%$ to $2 \%$ of the reasons for consultation in the emergency services [14].

Total hematuria represented $7.28 \%$ of the reasons for consultation in our series. This result is comparable to that reported by Fall in Senegal which was 7.1\% [6]. Hematuria is the main sign of bladder tumors [15]. The bladder tumor was the first cause of hematuria in our context, the country being located in an area of bilharzian endemic.

Twist of the spermatic cord accounted for $4.21 \%$ of urological emergencies in our series. Martin, Tfeil and Fall respectively reported a frequency of $0.8 \%$ $2.92 \%, 2.8 \%$ [4] [5] [6]. The average age of the patients was 22.18 years with extremes of 5 years and 43 years. Twisting of the spermatic cord can occur at any age, but the average age of onset is between 16 and 22 years. Which corresponds to the average age in our series [16].

Urogenital trauma accounted for $6.51 \%$ of urological emergencies in our series. Trauma to the urethra was the most common (47.06\%). Our result is comparable to that of Diallo which reported a frequency of $7 \%$ [1].

The most performed surgical procedure in our series was suprapubic cystostomy in $24.1 \%$ of the cases. Tfeil in Mauritania, Fall in Senegal and Topaktas in Pakistan made the same observation with $59.67 \%, 59.8 \%$ and $22.3 \%$ of cases [5] [6] [10]. In Burkina Faso, suprapubic cystostomy accounted for $77.5 \%$ of surgical procedures performed in urological emergencies [17]. In the same study, Zango reported 5 cases of peritoneal breach during suprapubic cystostomy, including one case of generalized acute peritonitis which led to the patient's death. It was a cystostomy performed under local anesthesia [17]. In other words, it is far from trivial. The suprapubic cystocatheter has less morbidity than a cystostomy. However, it is not widely used in our context due to its unavailability. Also, compliance with the rules of catheterization by students and nurses could help reduce the indications for suprapubic cystostomy. It is generally difficult surveys that arrive at CHUR, the other bladder retentions being taken care of in peripheral health units.

\section{Conclusion}

Urological emergencies occupy a significant place in our work context. As in most studies, bladder retention is the most common urological emergency. Our study shows that it is the elderly who are mainly concerned. An increase in the number of urologists would improve the handling of these emergencies. Also, the creation of a specific unit for urological emergencies will relieve the emergency reception service.

\section{Conflicts of Interest}

The authors declare no conflicts of interest regarding the publication of this paper. 


\section{References}

[1] Bobo Diallo, A., Bah, I., Diallo, T.M.O., Bah, O.R., Amougou, B., Bah, M.D., et al. (2010) Le profil des urgences urologiques au CHU de Conakry, Guinée. Progrès en Urologie, 20, 214-218. https://doi.org/10.1016/j.purol.2009.10.008

[2] Talreja, S., Banerjee, I., Teli, R., Agarwal, N., Vyas, N., Priyadarshi, S., et al. (2015) A Spectrum of Urological Emergency Reported at a Tertiary Care Teaching Hospital: An Experience. Journal of Clinical and Diagnostic Research, 9, PC12-5. https://doi.org/10.7860/JCDR/2015/15793.6821

[3] Diabaté, I., Ondo, C.Z., Sow, I., Ba, A. and Mboup, C. (2015) Les urgences urologiques au centre hospitalier de Louga, Sénégal: Aspects épidémiologiques et évaluation de la prise en charge. African Journal of Urology, 21, 181-186. https://doi.org/10.1016/j.afju.2015.04.004

[4] Martin, L., Pillot, P., Bardonnaud, N., Lillaz, J., Chabannes, E., Bernardini, S., et al. (2014) Évaluation de l'activité d'une unité d'urgences urologiques en centre hospitalier universitaire. Progrès en Urologie, 24, 62-66. https://doi.org/10.1016/j.purol.2013.06.004

[5] Tfeil, Y.O., Elmoctar, C.A.O., Ca, M.O. and Jdoud, C.O. (2010) Les urgences urologiques au centre hospitalier national de Nouakchott: Aspects épidémiologiques, cliniques et thérapeutiques. Basic and Clinical Andrology, 20, 144. https://doi.org/10.1007/s12610-010-0077-4

[6] Fall, B., Diao, B., Fall, P.A., Diallo, Y., Sow, Y., Ondongo, A.A.M., et al. (2008) Les urgences urologiques en milieu hospitalier universitaire à Dakar: Aspects épidémiologiques, cliniques et thérapeutiques. Progrès en Urologie, 18, 650-653. https://doi.org/10.1016/j.purol.2008.04.004

[7] Mpirimbanyi, C., Nyirimodoka, A., Lin, Y., Hedt-Gauthier, B.L., Odhiambo, J., Nkurunziza, T., et al. (2017) Emergency General Surgery in Rwandan District Hospitals: A Cross-Sectional Study of Spectrum, Management, and Patient Outcomes. BMC Surgery, 17, 121. https://doi.org/10.1186/s12893-017-0323-X

[8] Mondet, F., Chartier-Kastler, E., Yonneau, L., Bohin, D., Barrou, B. and Richard, F. (2002) Epidemiology of Urological Emergencies in a Teaching Hospital. Progrès en Urologie, 12, 437-442.

[9] Diabaté, F., Ouédraogo, B., Sow, I. and Bâ, A. (2015) Cystostomie percutanée à la pince de Kelly: Indications, technique et résultats. The Pan African Medical Journal, 22, 164. https://doi.org/10.11604/pamj.2015.22.164.7280

[10] Topaktaş, R., Altın, S., Aydın, C., Akkoç, A. and Yılmaz, Y. (2014) Retrospective Evaluation of Urological Admissions to Emergency Service of a Training and Research Hospital. Turkish Journal of Urology, 40, 216-220. https://doi.org/10.5152/tud.2014.77861

[11] Sarkis, P., Farran, F., Khoury, R., Kamel, G., Nemr, E., Biajini, J. and Merheje, S. (2009) Gangrène de Fournier: Revue de la littérature récente. Progrès en Urologie, 19, 75-84. https://doi.org/10.1016/j.purol.2008.09.050

[12] Katib, A., Al-Adawi, M., Dakkak, B. and Bakhsh, A. (2013) A Three-Year Review of the Management of Fournier's Gangrene Presented in a Single Saudi Arabian Institute. Central European Journal of Urology, 66, 331-334.

https://doi.org/10.5173/ceju.2013.03.art22

[13] Kuzaka, B., Wróblewska, M.M., Borkowski, T., Kawecki, D., Kuzaka, P., Młynarczyk, G., et al. (2018) Fournier's Gangrene: Clinical Presentation of 13 Cases. Medical Science Monitor, 24, 548-555. https://doi.org/10.12659/MSM.905836 
[14] El Khebir, M., Fougeras, O., Le Gall, C., Santin, A., Perrier, C., Sureau, C., et al. (2009) Updating 2008 of 8th Conference of Consensus of the French Society of Medical Emergencies of 1999. The Treatment of Adult Renal Colic by the Emergency Services and in ER. Progrès en Urologie, 19, 462-473.

https://doi.org/10.1016/j.purol.2009.03.005

[15] Diao, B., Amath, T., Fall, B., Fall, P.A., Diémé, M.J., Steevy, N.N., et al. (2008) Les cancers de vessie au Sénégal: Particularités épidémiologiques, cliniques et histologiques. Progrès en Urologie, 18, 445-448.

https://doi.org/10.1016/j.purol.2008.04.016

[16] Bah, O.R., Roupret, M., Guirassy, S., Diallo, A.B., Diallo, M.B. and Richard, F. (2010) Aspects cliniques et thérapeutiques de la torsion du cordon spermatique: Etude de 27 cas. Progrès en Urologie, 20, 527-531.

https://doi.org/10.1016/j.purol.2009.12.011

[17] Zango, B., Kaboré, F.A., Kaboré, M., Kirakoya, B., Ky, D.B., Kabré, B., et al. (2011) Suprapubic Cystostomy at Urological Emergency Unit of CHU-YO, Ouagadougou, Burkina Faso: Indications, Technique and Complications. Open Journal of Urology, 6, 67-71. https://doi.org/10.4236/oju.2016.64013 